
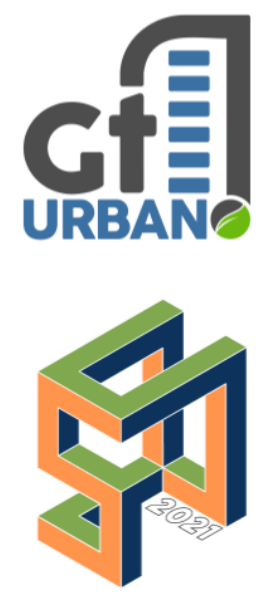

SINGEURB

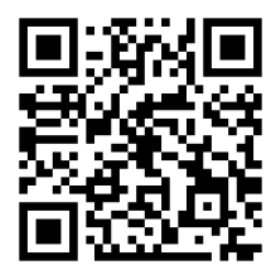

Como citar:

IGNACIO, Marcus V. L.; VIEIRA, Douglas; CALAIS, Felipe.

Efeitos do uso do aplicativo Waze em uma via local na cidade de São Paulo. In: III SIMPÓSIO NACIONAL DE GESTÃO E

ENGENHARIA

URBANA:

SINGEURB, 2021, Maceió. Anais...

Porto Alegre: ANTAC, 2021. p. 425-

430.

Disponível em: https://eventos.antac. org.br/index.php/sin geurb/issue/view/14

\title{
Efeitos do uso do aplicativo Waze em uma via local na cidade de São Paulo
}

\author{
The effects of waze application use in a local \\ street at the city of São Paulo
}

Marcus V. L. Ignacio, Universidade Anhembi Morumbi,

marcusv.lignacio@gmail.com

Douglas Vieira, Universidade Anhembi Morumbi, douglasvieiranpd@outlook.com

Felipe Calais, Universidade Anhembi Morumbi, felipe-calais@hotmail.com

\section{RESUMO}

A frota de automóveis particulares na Grande São Paulo aumentou 22,8\% entre 2007 e 2017. Igual crescimento não se observou no sistema viário ou no sistema de transporte público, levando a população a buscar formas de tornar os deslocamentos mais rápidos e confortáveis. Em particular, ganharam popularidade entre motoristas aplicativos que avisam sobre vias congestionadas ou interditadas, reduzindo o tempo de viagem. Todavia, se por um lado os aplicativos aumentam a conveniência do motorista por reduzir o seu tempo de viagem, por outro ignora a organização funcional do sistema viário da cidade e acaba por levar às vias locais, localizadas nos miolos dos bairros, elevados volumes de tráfego, dado que estas são consideradas rotas de fuga dos congestionamentos. Neste sentido, o trabalho se propõe a avaliar o impacto do uso do aplicativo Waze em uma via localizada no bairro da Vila Nova Conceição, com a contagem dos volumes de tráfego observados em diferentes trechos da via. Por meio da comparação com os Volumes Diários Médios esperados para uma via local, constatou-se que a via tem sido utilizada como alternativa para a principal via arterial da região, preterida nos horários de pico por conta dos engarrafamentos.

Palavras-chave: Mobilidade urbana, Congestionamentos, Sistema viário.

\section{ABSTRACT}

The number of private cars in São Paulo Metropolitan Area increased by 22,8\% between 2007 and 2017. However, the same growth was not observed in the city road system or in the public transportation service, leading population to seek ways to have faster and more comfortable displacements. In this sense, some smartphones apps became popular among drivers by advising them about traffic jams and blocked roads, reducing travel times. On the other hand, in despite of improving mobility conditions, these technologies ignore the organization of cities road systems and increases traffic flow in local streets, which are converted in escape routes for traffic jams. This paper proposes an evaluation about the impact of using the Waze application on a road located at Vila Nova Conceição neighborhood, counting the traffic volumes observed in different stretches of the road. The comparison to expected flows for a local road shows that the road has been used as an alternative to the main arterial road in the region, which is neglected at peak times due to traffic jams.

Keywords: Urban mobility, Traffic jams, Road system. 


\section{INTRODUÇÃO}

Apesar da importância econômica e de concentrar 20,8 milhões de habitantes em sua Região Metropolitana, as melhorias na infraestrutura dos sistemas de transporte de São Paulo ocorrem em ritmo lento. Por outro lado, a frota metropolitana de automóveis particulares, segundo a pesquisa Origem-Destino de 2017, cresceu mais de $200 \%$ nos últimos 40 anos. À população, cabe a busca por alternativas que supram a ineficácia das ações do setor público de modo a garantir condições satisfatórias de mobilidade dentro da cidade ou na Região Metropolitana.

Neste sentido, aplicativos para smartphones têm se destacado por oferecerem à população serviços como tempo de espera nos pontos de ônibus e informações sobre itinerários e vias congestionadas. Dentre esses aplicativos, destaca-se o Waze, popularmente conhecido e utilizado pelos motoristas paulistanos, cujo princípio de funcionamento está no compartilhamento de informações em tempo real, notificando os motoristas sobre possíveis congestionamentos, acidentes e interdições de vias. Deste modo, o aplicativo disponibiliza rotas alternativas e ágeis, levando à redução do tempo de deslocamento no trajeto origemdestino de seus usuários, ainda que sejam disponibilizadas para o motorista vias locais, inadequadas para receber elevados volumes de tráfego.

Vias locais, segundo a prefeitura de São Paulo, são vias destinadas predominantemente ao fluxo de pedestres e nas quais os veículos devem trafegar a velocidades abaixo dos $40 \mathrm{~km} / \mathrm{h}$. O uso de áreas residenciais como rotas de fuga para automóveis pode trazer transtornos sob a perspectiva urbana, como poluição sonora e poluição atmosférica, deterioração precoce do pavimento e aumento nos riscos na travessia de pedestres. A partir da identificação das vias que apresentam aumento no volume de tráfego, é possível definir estratégias que auxiliem na melhor organização, não somente do sistema viário, mas também dos sistemas de transporte de toda a cidade de modo a oferecer à população alternativas de deslocamento com menor impedância.

\section{OS EFEITOS NOCIVOS DA HEGEMONIA DO AUTOMÓVEL EM SÃO PAULO}

Dados do Departamento de Trânsito de São Paulo (Detran-SP) ajudam no entendimento do cenário de saturação no sistema viário da cidade. Segundo Detran (2018), no período entre 1997 e 2017, houve um acréscimo de $82 \%$ na frota de veículos apenas na capital paulista e um crescimento de $161 \%$ na frota de todo o estado de São Paulo. Outrossim, menciona Vasconcellos (2012) que os grandes congestionamentos observados na Região Metropolitana de São Paulo são fruto de diversas políticas de incentivo à utilização do automóvel uma vez que, historicamente, o que se observa na cidade de São Paulo é a construção de grandes vias de modo a reduzir os congestionamentos.

Prossegue Vasconcellos (2012) que os automóveis receberam, historicamente, todo o tipo de incentivo para que ocupassem os espaços viários e fossem a forma de locomoção preferida em cidades como São Paulo. Outrossim, complementa que também as autoridades de trânsito atuaram no sentido de melhorar a gestão do trânsito, melhorando o fluxo de tráfego, na maioria das vezes em detrimento da segurança de áreas residenciais e da qualidade de vida. Na maioria dos bairros, as vias locais de acesso foram reestruturadas, tornando-se vias de mão única, permitindo o desenvolvimento de altas velocidades e fluxo pesado de automóveis, causadores de prejuízos sociais e ambientais. 
O Código de Trânsito Brasileiro, Lei no 9.503/97, estabelece, em seu artigo 60, a classificação viária das vias abertas à circulação. Na cidade de São Paulo, a Portaria no 18/2019 define como vias locais aquelas destinadas ao acesso local, sem tráfego de passagem e preferencialmente localizadas em áreas residenciais.

Com o objetivo de avaliar os efeitos que o uso do aplicativo Waze gera ao ignorar a organização funcional do sistema viário, decidiu-se pela escolha de uma rota que contemplasse, em condições adequadas de fluidez no tráfego, um sistema arterial além das vias coletoras e locais presentes nos extremos do deslocamento. Com extensão de 8,9 quilômetros, o trecho tem como origem a Rua Treze de Maio, nº 1.266,

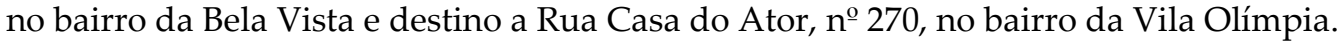

Este trajeto foi realizado ao longo de uma semana, em dias úteis, com saída às 17 horas e seguindo as premissas da organização funcional do sistema viário da cidade de São Paulo. Desta forma, o trajeto priorizou, para os trechos mais longos do percurso, as vias arteriais, dentre elas a Av. 23 de Maio e o Túnel Ayrton Senna. Um segundo trajeto possível é por meio da Av. República do Líbano, também classificada pela prefeitura de São Paulo como via arterial. A Figura 1 identifica o trajeto e os segmentos arteriais citados. O tempo médio de percurso foi de 1 hora e 17 minutos, com os sistemas arteriais congestionados.

Figura 1 - Trajeto sobre vias arteriais

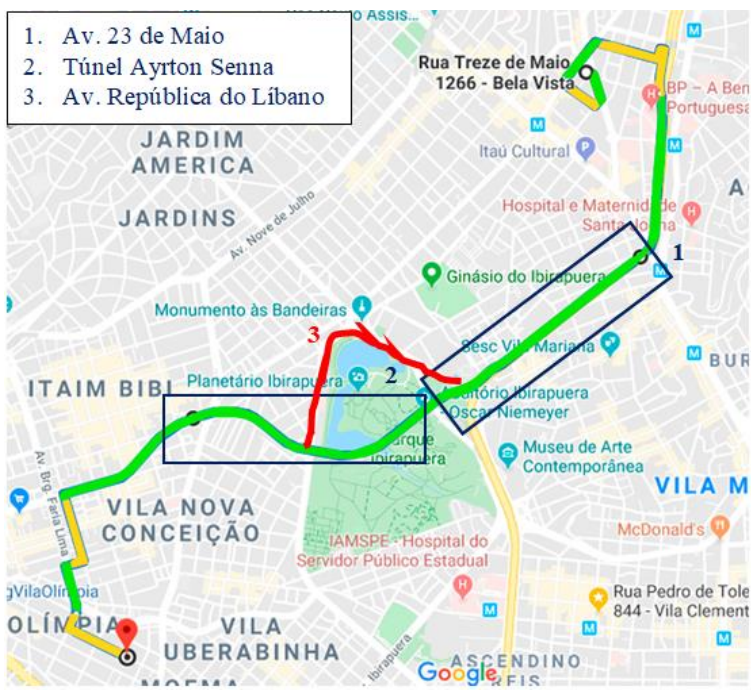

Fonte: Google e autores (2020)

O Waze, por sua vez, ofereceu, em todos os testes realizados ao longo da mesma semana e com saída no mesmo horário, uma rota alternativa de 7,8 quilômetros de extensão, com tempo estimado de percurso em 42 minutos e velocidade média de $11 \mathrm{~km} / \mathrm{h}$. A Tabela 1 apresenta a comparação entre o trajeto convencional, segundo os critérios de organização do sistema viário, e o trajeto proposto pelo aplicativo Waze. 
Tabela 1 - Comparação entre os trajetos

\begin{tabular}{cccc}
\cline { 2 - 4 } & $\begin{array}{c}\text { Trajeto } \\
\text { convencional }\end{array}$ & $\begin{array}{c}\text { Trajeto } \\
\text { via Waze }\end{array}$ & Ganho \\
\hline Extensão $(\mathrm{km})$ & 8,9 & 7,8 & Redução de 14\% \\
$\begin{array}{c}\text { Tempo de percurso } \\
(\mathrm{min})\end{array}$ & 77 & 42 & Redução de $45 \%$ \\
$\begin{array}{c}\text { Velocidade média } \\
(\mathrm{km} / \mathrm{h})\end{array}$ & 7 & 11 & Aumento de $57 \%$ \\
\hline
\end{tabular}

Fonte: os autores

No cenário descrito, o ganho de tempo no trajeto ocorreu pelo fato de o Waze ter direcionado o motorista para a Rua Escobar Ortiz (Figura 2), no bairro da Vila Nova Conceição. O desvio para este logradouro evitou o tráfego nos corredores arteriais do Túnel Ayrton Senna e da Av. República do Líbano, congestionados nos dias e períodos avaliados.

Ainda que, segundo a CET-SP (2019), a Rua Escobar Ortiz seja classificada como via coletora, a análise do logradouro em toda a sua extensão mostrou características comuns nas vias classificadas como locais, segundo DNIT (2010) e o Código de Trânsito Brasileiro:

- $\quad$ estacionamento permitido 24 horas e em ambos os sentidos;

- $\quad$ fluxo de pedestres livre e aleatório;

- $\quad$ ausência de semáforos nos cruzamentos;

- $\quad$ velocidade máxima regulamentada de $30 \mathrm{~km} / \mathrm{h}$;

- $\quad$ acesso livre às propriedades adjacentes.

Figura 2 - Trajeto sugerido pelo Waze

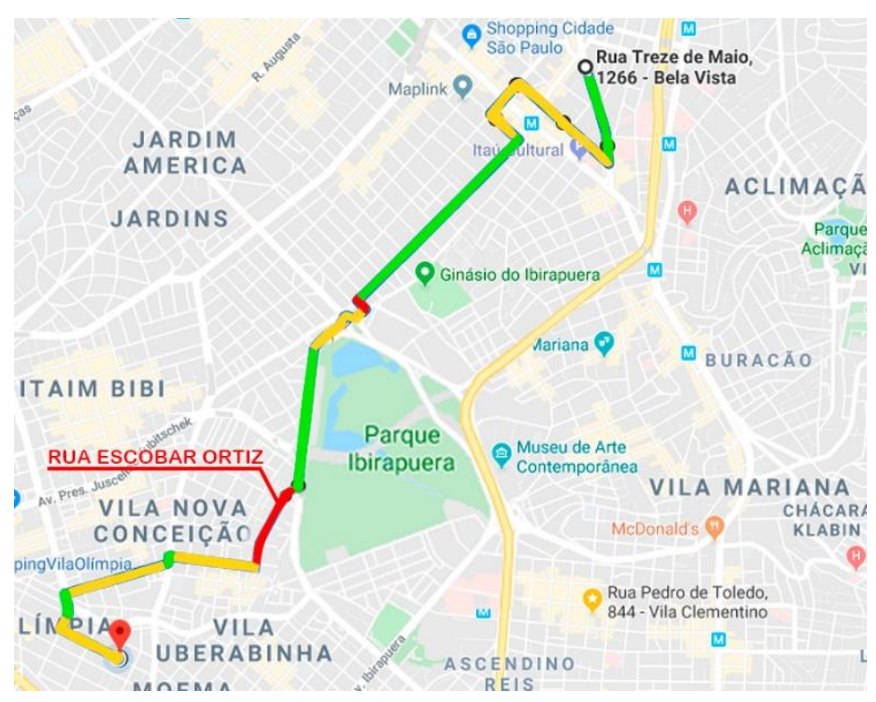

Fonte: Google e os autores (2020) 
De modo a verificar se a Rua Escobar Ortiz estava sendo utilizada como rota de fuga dos congestionamentos, foram realizadas contagens volumétricas de tráfego ao longo de uma semana, em dias úteis, no período das $17 \mathrm{~h}$ às $18 \mathrm{~h}$. A razão pela escolha do horário se deve ao fato de que, neste período do dia, a Av. República do Líbano, via arterial paralela, apresenta fluxo congestionado. Adicionalmente, foram contados, nos mesmos dias, os volumes entre $14 \mathrm{~h}$ e 15h, horário em que os trajetos sugeridos pelo Waze não elegem a Rua Escobar Ortiz como parte do trajeto. Em cada hora, os volumes foram contados em períodos de 15 minutos e a Figura 3 mostra a média das medições, em cada período.

Figura 3 - Volumes medidos na Rua Escobar Ortiz

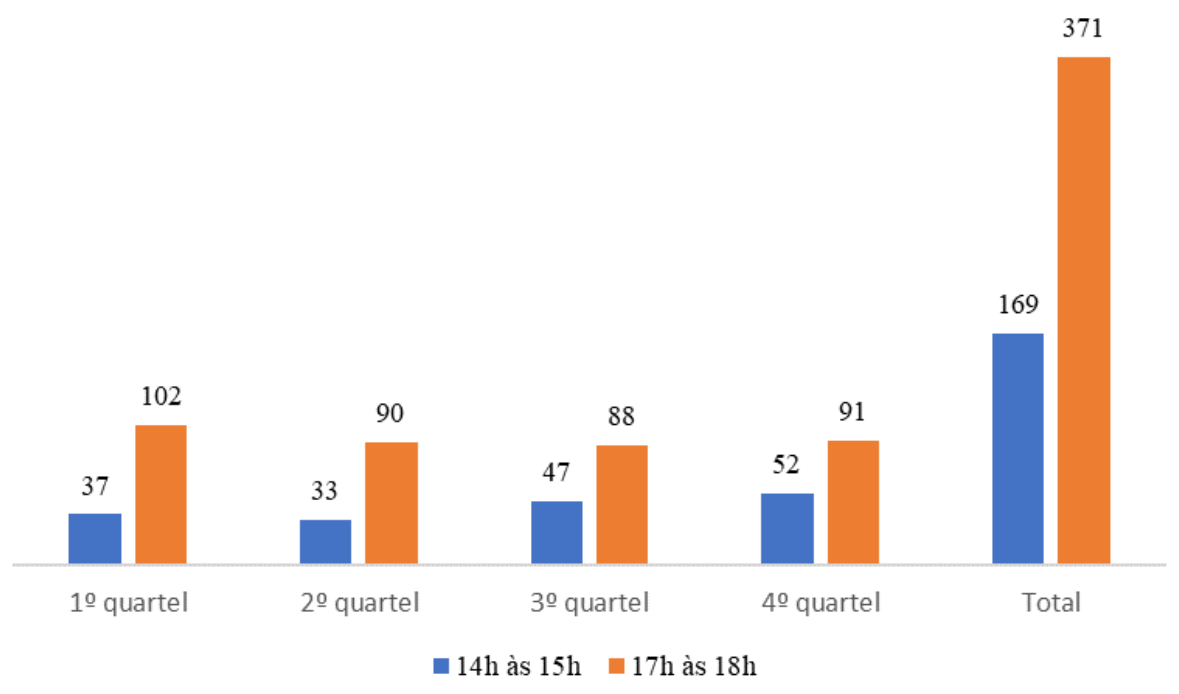

Fonte: os autores (2020)

A instrução de projeto no 02/2004 da Prefeitura de São Paulo define que, para vias locais, o Volume Diário Médio (VDM) deve estar compreendido entre 100 e 400 veículos, com predominância de tráfego leve. A contagem volumétrica na Rua Escobar Ortiz, no período compreendido entre 17h e 18h, além de ser quase $120 \%$ maior que no período compreendido entre 14h e 15h, está próxima do limite superior de VDM para uma via local. Outrossim, nos dias de contagem, o volume médio de 540 veículos, nos dois períodos, coloca a Rua Escobar Ortiz com um parâmetro de tráfego que já a coloca como via coletora.

O Manual de Projeto Geométrico de Travessias Urbanas do DNIT (2010) define as vias locais como aquelas destinadas aos deslocamentos mais curtos onde a prioridade é o acesso às propriedades. Uma vez que estas vias não têm requisitos de grande mobilidade e elevado nível de serviço, não se destinam ao tráfego de passagem. No entanto, a Rua Escobar Ortiz, na medida em que se converte em caminho sugerido pelo aplicativo Waze, passa a atender o tráfego de passagem que evita as vias arteriais saturadas. $\mathrm{O}$ uso do sistema local como sistema arterial gera riscos ao fluxo de pedestres, dificuldade de estacionamento e acesso às atividades lindeiras à via e prejuízos à qualidade de vida local, sobretudo em áreas residenciais.

\section{CONCLUSÃO}

O uso de vias locais como rotas de fuga de congestionamentos é sintoma não apenas da falta de capacidade do sistema viário paulistano, mas também resulta de um processo histórico de expansão urbana sem 
controle, dado que regiões mais distantes do centro expandido ainda não contam com sistema de transporte de qualidade e com maior capacidade, como trens e metrô.

Em áreas urbanas, a importância do sistema viário é definida pela natureza do tráfego que ela atende. Os desejos de deslocamento da população estão associados a necessidades essenciais à sua sobrevivência: trabalho, educação, lazer, entre outros. Em cidades como São Paulo, em que os postos de trabalho não se distribuem de forma homogênea sobre o território, haverá parcela da população à qual restarão extensos deslocamentos diários, muitos deles realizados sobre o modo motorizado individual em ruas e avenidas de baixa capacidade viária.

Para além da necessidade de investimentos na melhoria dos sistemas de transporte na cidade de São Paulo e na Região Metropolitana, ressalta-se que a atuação dos gestores públicos não deve se restringir à gestão dos sistemas de transporte. Discussões acerca de como a cidade se organiza e acomoda suas atividades econômicas também podem diminuir os custos dos congestionamentos e lotação do transporte público. Daí a importância de leis que orientem o desenvolvimento e o crescimento da cidade, como o Plano Diretor e a Lei de Parcelamento, Uso e Ocupação do Solo (LPUOS).

\section{REFERÊNCIAS}

BRASIL - Lei no 9.503 - Código de Trânsito Brasileiro. 1997.

COMPANHIA DE ENGENHARIA DE TRÁFEGO (CET-SP) - Instrução de Projetos no 2 - Classificação das vias. São Paulo, 2001.

DNIT - Publicação IPR 740 - Manual de Projeto Geométrico de Travessias Urbanas. Departamento Nacional de Infraestrutura de Transportes, Instituto de Pesquisas Rodoviárias, Rio de Janeiro, 2010.

DETRAN SP - Departamento Estadual de Trânsito de São Paulo. Frota de veículos da cidade de São Paulo. Departamento Estadual de Trânsito de São Paulo, 2018.

IBGE - Instituto Brasileiro de Geografia e Estatística. Panorama da cidade de São Paulo. Disponível em: https://cidades.ibge.gov.br/brasil/sp/sao-paulo/panorama. Acesso em: 05 jun. 2021.

SÃO PAULO - Companhia do Metropolitano de São Paulo. A mobilidade urbana da Região Metropolitana de São Paulo em detalhes. Disponível em: <http://www.metro.sp.gov.br/ pesquisaod/arquivos/Ebook\%20Pesquisa\%20OD\%202017_final_240719_versao_4.pdf>. Acesso em: 17 mai. 2020.

- Metropolitana de São Paulo em detalhes: pesquisa de Origem-Destino. Disponível em: $<$ http://www.metro.sp.gov.br/pesquisa-od/arquivos/Ebook\%20Pesquisa\%20OD\%202017___ final_ 240719_versao_4.pdf>. Acesso em: 17 mai. 2020.

VASCONCELLOS, E. A. Mobilidade urbana e atividade econômica. In: Comin, A.; Freire C.T.; Kneip, S. A.; Wissenbach, T. C. (orgs.) Metamorfoses Paulistanas. Editora Unesp: São Paulo, 2012, p. 245-263. 